\title{
USE of mesenchymal stem cells extracted from the patient own adipose tissue for the treatment of degenerative pathology
}

\author{
Arrotegui I* \\ Department of Neurosurgery, Consortium University General Hospital of Valencia, Spain
}

\section{Introduction}

\section{What is regenerative medicine}

It is the field of research and clinical applications focused on the repair and regeneration of cells, tissues or organs with the purpose to restore damaged functions. New techniques in regenerative medicine use adult mesenchymal cells (stem cells contained in the Stromal Vascular Fraction or SVF of the adipose tissue of the actual patient for the cellular regeneration.

\section{What are the stem cells}

The human body is formed by different types of cells and each one of them fulfils a specific function so that the organism work properly. The cells that originate all these types of skilled cells are the stem cells.

Stem cells can divide, differentiate and car renew producing more stem cells without losing his potential or giving place to different types of skilled cells.

\section{Perspective historica}

To explain the entire development of the stem cells since they were discovered until the actuality and this can see for greater ease in shape of list with his respective years and the distinct names of the scientists that contributed his advances.

- 1908: Russian Scientist proposes for the first time use the term stem cells after having discovered that existed in our body some able cells to generate blood cells.

- 1968: the first transplantation of medulla osseous is successfully performed with a view to treating an illness known like Immunodeficiency combined severe.

1978: stem cells in the umbilical cord of

Humans are discovered.

- 1981: stem cells in mice embryos are identified and separated.

- 1988: embryonic stem cells in hamsters are created.

- 1992: Stem cells of the nervous system are cultivated in vitro.

- 1997: the first sheep is cloned from stem cells.

- 2001: Scientists cloned the first human embryo, to produce embryonic stem cells.

- 2003: A new source of stem cells was discovered in the pulp of teeth of milk in children
- 2005: stem cells similar to those in the embryonic in the umbilical cord are identified.

- 2006: the first artificial hepatic cells of stem cells from the umbilical cord are created.

- 2008: pluripotent stem cells' from the gastric and hepatic cells of adult mice are created.

- 2008: The first study was published of successful regeneration of cartilage of knees using mesenchymatous stem cells in adults.

- 2009: President Obama approves research into stem cells.

Each one of these discoveries and advances have served to the researchers for his understanding and for the utilization of the cells as it is important to know the background work of precedes to leave a research body that stands out in the scientific field.

\section{Properties of a stem cell}

Stem cells can divide, differentiate and car renew producing more stem cells without losing his potential or giving place to different types of skilled cells (Figure 1).

They act in the regeneration or repair of the tissues damaged and substitute the cells that die by different reasons (traumatisms, illness, age, etc.).

The cell mother is an undifferentiated cell with capacity for car renewal and gives origin to cells differentiated from one or several lineages. The stem cells classify based on their potentiability. The stem cells that can differentiate (transform) in lines / specific cellular lineages (Muscular cells, adipose, of cartilage, of bone, of sinew, etc.) are the maternal mesenchymal cells.

Mesenchymal cells have identified and obtained different origins, for example the bone marrow by puncture, BMSC (Bone Marrow Stem Cells), or adipose tissue called ADSC (Adipose Derived Stem Cells). The ADSC, cells derivative of the adipose tissue are being focus of interest, since the adipose tissue white (commonly called "fat") is the most abundant source of Mesenchymal Mother Cells. Roughly, these

Correspondence to: Arrotegui I, Department of Neurosurgery, Consortium University General Hospital of Valencia, Avda tres cruces S/N, VLC-46014. Spain. E-mail: athbio@yahoo.es

Received: October 20, 2017; Accepted: November 10, 2017; Published: November 13, 2017 


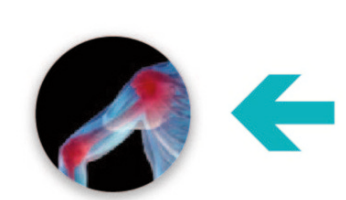

REDUCCIÓN DE LA INFLAMACIÓN

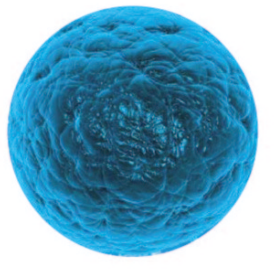

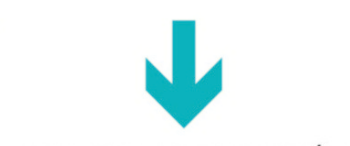

INMUNO-MODULACIÓN

MUNO-MODULACIÓN

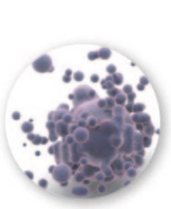

COMBATIR APOPTÓSIS

(Muerte celular)
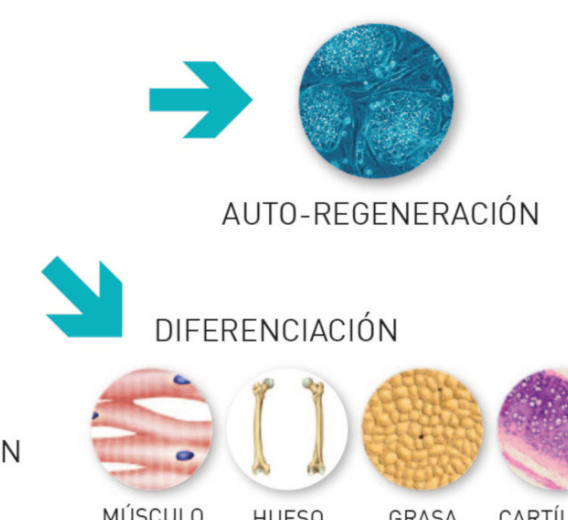

DIFERENCIACIÓN

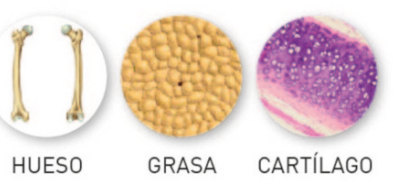

Figure 1. Stem Cell

are $1 \%$ of the human adipose cells in front of $0.0015 \%$ of the ones of bone marrow.

\section{Mesenchymal stem cells}

\section{Advantages in comparison with that obtained from the medulla osseous}

The quantity and feasibility of stem cells is greater in the fat that in the medulla osseous (bone).

The form of obtaining is easier, fast and less traumatic in the fat that of the medulla osseous. (Figure 2).

The stem cells mesenchymal contained in the obtaining of SVF or "fraction stromal vascular" of the adipose tissue have the same capacities and cellular markers that in the medulla osseous.

\section{Types of stem cells by his potenciabilidad}

\section{Totipotent (Embryonic)}

Cell with capacity to differentiate in the cells of the tissues of the three embryonic planes (ectoderm, mesoderm and endoderm), germinal lineage and vitalize sack, and extra-embryonic (placenta). They are able to generate a complete organism.

\section{Pluripotent (Embryonic)}

Cells capable of differentiating between the three embryonic planes (ectoderm, mesoderm and endoderm), germinal lineage and vitalize sack. They cannot generate a complete organism.

\section{Multipotent SVF and ADSC}

Cells capable of differentiating between distinct lineages and to generate only cells of their same plane or lineage mesoderm.

For example: SVF and ADSC (stem cells derived from the adipose tissue)

The use of Stem cells (SVF and ADSC) obtained from the fat manufacture by means of mini-liposuction out of all doubt in the applications of regenerative medicine. Characteristics of the SVF and ADSC

- Capacity to differentiate in distinct lineages and are very useful for the cellular therapy of tissue replacement (refers to multipotentiality [1,2].

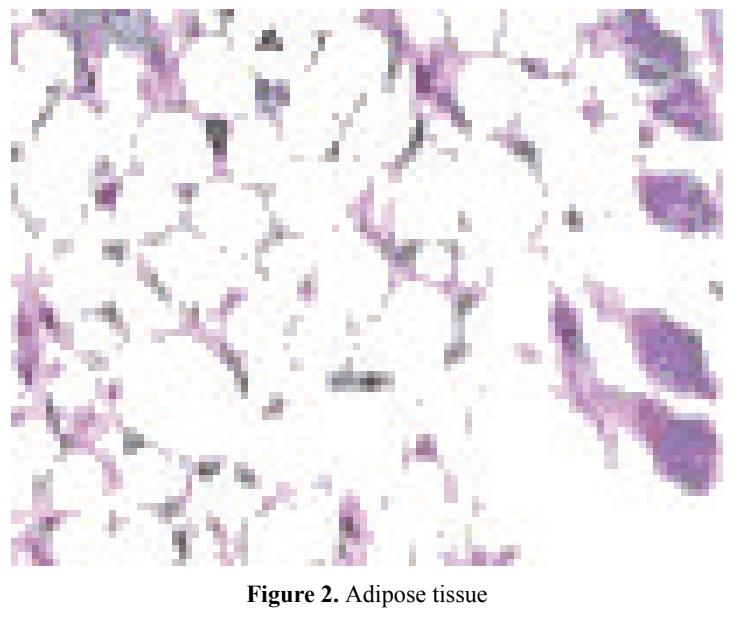

Table 1. Mix of nucleated cells

\begin{tabular}{|c|c|}
\hline 25 to $45 \%$ & hematopoietic cells. \\
\hline 15 to $30 \%$ & stromal cells / stem cells. \\
\hline 10 to $20 \%$ & endothelial cells. \\
\hline $5 \%$ & pericyte cells. \\
\hline
\end{tabular}

- They can be directly administered in the affected region where the cellular regeneration is intended or by systemic / intravenous routes [3].

- They can secrete soluble factors that promote the effect of paracrine and immuno-modulators that facilitate therapeutic effects $[4,5]$.

- They contain a fibroblastic morphology and possess properties of mesenchymal stem cells (MSC) the same as the ones traditionally isolated in bone marrow.

- They are immuno-privileged that allows to have a minimum immune reaction by the lack of expression of the immuhistocompatibility of class II. They display receptors that may be guided and are able to migrate to the places of the injury [6].

- They are cells aimed straight at the target organ.

- When fresh ADSC is isolated, a non-cultured heterogeneous population is obtained of SVF cells (Stromal Vascular Fraction) with certain therapeutic qualities that adapt better to the different clinical stages 


\section{What is SVF?}

The fraction stromal vascular is formed by different cells, amongst them, stem cells adults, with capacity to regenerate those tissues damaged so much by traumatisms as by the own aging and cellular wear. In the SVF of the adipose tissue, find big quantity and feasibility

Of stem cells with capacity regenerative to generate new adipose tissue and glasses

Blood as well as produce factors of growth that help to survive to the adipocytes and to the training of the vascular network [7].

\section{SVF Composition}

- Cells derived from the blood

- Cells derived from the adipose

- ADSC (Stem cells of the adipose tissue

- Endothelial cells

- Other cells

After the liposuction performed manually to isolate the cells SVF by means of the enzymatic reaction, the washing of enzymatic residue, centrifugation, we obtain the separation of adipocytes floating from a pellet (sediment) denser of SVF. The pellet of SVF contains cells derived from the blood, stem cells derived from the adipose tissue, endothelial cells and other cells that are found in the adipose tissue. They vary in each of the people studied.

In accordance with IFATS (International Federation of Adipose Therapeutics and Science) and ISCT .International

Furthermore, it is proven that the mix of SVF and autologous fats help to the angiogenesis in the healing of wounds, promotes the cellular differentiation, improving thus the vascularisation and the production of collagen

${ }^{\star}$ The potential that has the SVF (Stromal Vascular Fraction). 37\% of the cells no adipocytes are in the Stromal Vascular Fractionand that occupy the part

Drop of the centrifuge are the cells derivative mother of the adipose tissue (ADSC).

They have showed that the cells derivative mother of the adipose tissue achieve to differentiate in vitro in multiple lineages, between which find adipocytes, chondrocytes, hepatocytes and osteoblasts, in addition to endothelial, epithelial, hematopoietic, neural and myogenic cells

\section{Applications of SVF}

The greater number of patients drafted and / or reported have been for reconstruction procedures involving the breast (soft tissue) and repair of the fistula (illness of Crohn) [8].

In the case of the mammary reconstruction, the SVF autologous cells recombine with the own tissue liposuction of the patient with ends of graft of fat.1SVF, this has significant clinical potential for the treatment of diverse orthopaedic pathologies as has been observed in studies in humans. It is being used in the treatment of patients with osteoarthritis (OA), chondromalacia, break of the meniscus, osteonecrosis of the femoral head and injuries of the sinew [9].

\section{Potential uses of stem cells and SVF}

Muscular dystrophy

Osteoarthritis
Rheumatoid arthritis

Clavicle

Healing of wounds

Crohn's Disease

Vascular injury

Amyotrophic Lateral Sclerosis

Diabetic foot

\section{Therapeutic applications}

Regeneration of cartilage, pain relief, wound healing, treatment of cardiac chronic illnesses, diabetes mellitus, immuno-regulation, etc.

Plastic surgery and Aesthetic Medicine: Increase and reconstruction of breasts, correction of crease, anti-aging Facial and body, etc.

Specialties: Traumatology, spine surgery, urology, gynecology, etc.

Traumatology: osteoarthritis (OA), chondromalacia, meniscus breakage, osteonecrosis of the femoral head and injuries of the sinew, injuries of degenerative disks [10].

\section{Advantages of using SVF}

\section{For patients}

1. It leads to an increase in quality of care for non-invasive and outpatient treatment.

2. Positive social evolution due to not having to interrupt professional obligations.

\section{For medical services}

1. An important advance to the solution of some pathologies based on the concept of Regeneration and Repair of tissues (Illness of Crohn, Osteoarthritis, post mastectomy reconstruction, urinary incontinence, etc.).

2. Incorporation into the techniques used in cellular therapy and regenerative medicine.

\section{For the hospital}

1. The creation of a Cellular Therapy/Regenerative Medicine Unit is a major milestone in positioning it in the first places regarding the portfolio of services offered in comparison with other centres. It is a service that offers a plus in the catchment of new patients.

2. An important economic saving for the Hospital in surgical material (prosthesis, mat. Fungible, etc.) and in hospitable stays diminishing waiting lists by performing these as out-patients' procedures.

3. Ease of performing the procedure with a minimum investment in multiple devices (Traumatology, Plastic Surgery, Neurosurgery, Urology, etc.)

\section{How are stromal vascular fractions (svf) obtained?}

Through a small liposuction (mini-liposuction), usually of the abdominal zone or inner of the thigh, by his ease of access. The process realises with local anaesthesia. It is normally sufficient with a sample of 50 c.c. of adipose tissue and the patient will be able to return to their everyday life immediately.

A performance increase $22 \%$ of higher for the SVF cells was proven, when the sample of fat had been obtained from the trunk, in 
comparison to when it had been obtained from members of another part of the body.

\section{Extraction of the liposuction}

After disinfecting the donor site with povidone iodine and preparing the surgical field, injects mepivacaine to $1 \%$ in the inferior umbilical skin for incidence afterwards $3 \mathrm{~mm}$ with leaf of bistoury of the no11. It practiced a manual tumescent liposuction with anaesthetic formula of Klein modified $(500 \mathrm{mg}$ lidocaine $5 \%+12.5 \mathrm{meq}$ of $\mathrm{H} 2 \mathrm{CO} 3 \mathrm{Na}+1 \mathrm{mg}$ of adrenaline 1: 100.000 in 1 litre of Ringer Lactate cold), by means of tubes drilled into several orifices, of 3 and $4 \mathrm{~mm}$ of diameter and distinct design, connected to syringes of $50 \mathrm{~cm} 3$ in which it practices empty with brake. The mechanical disruption of the lobules of adipose tissue in the thickness of the deep compartment of the inferior hemiabdomen allows to obtain liposuction, that is transferred to lab tubes measuring $50 \mathrm{~cm} 3$, filling only $20 \mathrm{~cm}^{3}$ of their capacity.

\section{Apparatology for the process of obtaining of svf}

- Incubator. Centrifuge

- Flow Laminar

- KIT for Extraccion and processing

Protocol (Length: 1 Hour for $50 \mathrm{cc}$ of fat)

- Liposuction

- Preparation

- Fat+Solution of collagenase

- Incubator

- Insert KIT

- Centrifuge

- Separation Of cells SVF

- 3 times washed of Collagenase

- Filtration of waste products

- Completed

An independent laboratory has evaluated the Smart X kit for obtaining of the SVF by means of four samples that show its Cellular Headcount, Cellular Feasibility, Security and Efficiency compared with the manual system (laboratory culture).

The system kit is used to separate the fat, wash the enzyme, extract the SVF and stem cells and filter the waste products.

\section{Reproductibility/plagiarism}

The SMARTX Kit incorporates a single technology and is endorsed by international patents. (Patent 1 "concave plunger" and 2 "up \& down").

\section{High performance}

A cellular headcount of more than 700.000 nucleated cells is achieved by $1 \mathrm{cc}$. Cellular feasibility: $98.58 \%$ of nucleated cells (living cells).

This is achieved by means of a short circuit that guarantees a high final feasibility of the cells. The headcount and feasibility of the derived stem cells is maximised via the adipose tissue with the minimum loss of cells based in the following concepts: Minimising the cellular shearing and the thermal effect (Patent 1). Transfer of cells up and down cells using a soft method without employing specific pressure (Patent 2).

\section{Security}

This minimises air pollution during the process.

The transfer of kit to syringe is performed within an enclosed system, is both safe and efficient. enzymatic residue: 0 (After the $3^{\circ}$ process of wash does not remain any enzymatic residue).

\section{Economy}

Has the operative cost and of initial lower investment.

To realise all the process, minimum investment is solely required in: Equipment: Incubator / Thermo-stirrer + Centrifuge + Flow Laminar (optional).

Expendables: Single usage Smart kit.

\section{Human Resources}

Personnel with a basic training.

SUITABILITY / EASE OF USE:

Involves a very simple handling method that facilitates the doctor's work. Human resources: Requires qualified staff with basic training.

\section{Legality}

Compliant with all the legal requirements and European Directives on of CE markings.

\section{Current Regulations in force in Spain and Europe}

Regenerative Medicine, includes a large number of subspecialisations, each one of them with different legislation and laws that apply to them.

The medicine most widely seen within Regenerative Medicine is TRANSLATIONAL MEDICINE, that in these moments involves and uses 2 different techniques: extraction of growth factors (Plasma Rich in Platelets) of the venous blood of a patient and their autologous implantation in the same surgical act. Extract mesenchymal stem cells from human adult tissue, in our case, of a Stromal Vascular Fraction (SVF - Stromal Vascular Fraction), that can be obtained from: adipose tissue (with a percentage of ADSC - Adipose Derived Stem Cells), from bone marrow (with percentage of BMSC - Bone Marrow Stem Cells).

For the techniques involving extraction and of infiltration, commonly used, to be found within inside the Spanish and European regulations, these must be carried out with certain requirements, these are: Not being able to subject to the biological tissue to what is known as substantial manipulation, and that this is duly stipulated by European wide legislation.

Will have to realise his implantation in a zone where also exist the same Stromal Vascular Fraction (SVF).

Also, it will have to carry out the process and the technician in the same surgical act, not being able to take out or move the biological tissue of the room of extraction, that will be always, an operating theatre.

Finally, it is technician can only be used in an autologous manner, this is, the tissue extracts and gives back to the same person. 
All this places to the technician used inside the designated Medicine or Therapy Translational.

It is currently "preferred" to obtain mesenchymal stem cells from the patient's abdominal fat, owing of their advantages, the high viability of the cells existing in that donor area, their easy access and little or no surgical complications. If the therapy is performed in this way, with the corresponding protocols of clinical best practices and within an enclosed circuit, maintaining always and strictly sterility, all the legal effects of Translational Medicine will be complied with, as per Royal Decree $1301 / 2006$ passed on the $10^{\text {th }}$ November and its subsequent replacement, RD $9 / 2014$ passed on the $4^{\text {th }}$ of July 2014.

\section{References}

1. Moseley TA, Zhu M, Hedrick MH (2006) Adipose-derived stem and progenitor cells as fillers in plastic and reconstructive surgery. Plast Reconstr Surg 118: 121S-128S. [Crossref]

2. Matsumoto D, Shigeura T, Sato K, Inoue K, Suga H, et al. (2007) Influences of preservation at various temperatures on liposuction aspirates. Plast Reconstr Surg 120: 1510-1517. [Crossref]
3. Suga H1, Matsumoto D, Inoue K, Shigeura T, Eto H, et al. (2008) Numerical measurement of viable and nonviable adipocytes and other cellular components in aspirated fat tissue. Plast Reconstr Surg 122: 103-114. [Crossref]

4. Charles-de-Sá L, Gontijo-de-Amorim NF, Maeda Takiya C, Borojevic R, Benati D, et al. (2015) Antiaging treatment of the facial skin by fat graft and adipose-derived stem cells. Plast Reconstr Surg 135: 999-1009. [Crossref]

5. Gimble J, Guilak F (2003) Adipose-derived adult stem cells: isolation, characterization, and differentiation potential. Cytotherapy 5: 362-369. [Crossref]

6. Hauner H, Entenmann G, Wabitsch M, Gaillard D, Ailhaud G, et al. (1989) Promoting effect of glucocorticoids on the differentiation of human adipocyte precursor cells cultured in a chemically defined medium. $J$ Clin Invest 84: 1663-1670. [Crossref]

7. Katz AJ, Tholpady A, Tholpady SS, Shang H, Ogle RC (2005) Cell surface and transcriptional characterization of human adipose-derived adherent stromal (hADAS) cells. Stem Cells 23: 412-423. [Crossref]

8. Miranville A, Heeschen C, Sengenès C, Curat CA, Busse R, et al. (2004) Improvement of postnatal neovascularization by human adipose tissue-derived stem cells. Circulation 110: 349-355. [Crossref]

9. Mitchell JB1, McIntosh K, Zvonic S, Garrett S, Floyd ZE, et al. (2006) Immunophenotype of human adipose-derived cells: temporal changes in stromal-associated and stem cellassociated markers. Stem Cells 24: 376-385. [Crossref]

10. Restorative Cardiac Function (2014) The American Journal of Medicine 127

Copyright: @2017 Arrotegui I. This is an open-access article distributed under the terms of the Creative Commons Attribution License, which permits unrestricted use, distribution, and reproduction in any medium, provided the original author and source are credited. 